\title{
Dominance behavior in socially isolated rats ${ }^{1}$
}

INGEBORG L. WARD, Villanova University, Villanova, Pa. 19085, and ARNOLD A. GERALL, Tulane University, New Orleans, La.

Male rats, socially isolated from 14-90 days of age, were found to be dominant over socially raised littermates when competing for food. The effect was attributed to the development of a response hierarchy during isolation which favored winning in the particular competition situation used in the present study.

The effect of early social isolation on the display of adult dominance and aggressive behavior has not been clearly delineated. Isolated mice have been reported to be both more aggressive (Ginsburg \& Allee, 1942; Kahn, 1954) and less aggressive (King \& Gurney, 1954; Hutchinson, Ulrich, \& Azrin, 1965) than socially reared mice. Rosen (1961) found no significant differences between socially reared and isolated rats in competition for water. In a recent study Uyeno \& White (1967) demonstrated that isolated animals were significantly dominant over socially reared Ss in competition tests made with survival motivation. They suggested that animals reared in isolation are handicapped in competition situations by initial naivety in a highly novel testing environment. When animals are allowed to adapt to the test situation prior to competition testing, according to their study, isolated Ss tend to dominate socially reared peers. The present study was designed to examine dominance behavior of rats with previously demonstrated social isolation effects against socially reared littermates. As in Uyeno and White's study, familiarity with the test situation was provided but a positive rather than aversive drive was used to instigate competition.

\section{METHOD}

Six of the 12 male Sprague-Dawley rats used as Ss were socially isolated from 14-90 days of age. Complete isolation was ensured by placing each $S$ into a Polystyrene ice-chest with a blower which provided ventilation and a masking noise. Six social littermates were also weaned at 14 days of age and housed in the same type of cage in groups of three animals. The rearing conditions have previously been described in detail by Gerall, Ward, \& Gerall (1967). Beginning at 90 days of age, animals were tested for sexual behavior in 20 min periods for five weeks. All the socials but none of the isolates copulated normally (Gerall et al, 1967). Ss were approximately 140 days old at the beginning of this study.

The apparatus, designed and provided by Prof. Loh Seng Tsai, consisted of a $37 \times 2 \times 2$ in. enclosed runway with a Plexiglas lid through which the $S$ could be observed. The inner dimensions of the runway were sufficiently small to enable passage for one rat. In the center of the runway was a removable wood barrier and on either end of the runway was a $12 \times 7 \times 7$ in. box which served either as a goal or start box. The entire apparatus was painted flat gray.

At approximately 140 days of age, each social animal was partitioned from its neighbor by a wire screen while isolated animals continued to be totally socially isolated. A 22-h food deprivation schedule was initiated three days before training and maintained through the study. Animais were fed daily in a separate cage located within the dimly illuminated running room. At no time during the study was food placed in the home cage.

Each $\mathbf{S}$ was initially adapted to eating in the goal boxes by permitting it to remain in a goal box until two $97 \mathrm{mg}$ food pellets, which served as standard reinforcement. were consumed. Three trials were given in each of the two goal boxes on two days, spaced four days apart. As during all other phases of this study, Ss were run consecutively and placed in an empty feeding cage between trials. Following the last day of goal box adaptation, three consecutive days of preliminary runway trials were given during which Ss were placed twice a day in the start box and allowed to traverse the runway to the opposite box for a food reward. Ss not leaving the start box within $2 \mathrm{~min}$ were placed into the runway and prevented from retracing by closing the entrance to the start box. Following this, eight consecutive days of runway training ensued. Six trials per day were given with an equal number of trials to each box presented in random order. Time to leave the start box and time to traverse the runway were recorded with a stop watch. Two days later, four consecutive days of six trials/day were presented as before. During this phase, the partition was inserted in the middle of the runway and Ss gradually learned to tolerate a 5-20 sec delay before it was removed, allowing them to proceed to the opposite goal box.

During the next four days, animals to compete against each other were placed in opposite start boxes and allowed to run to the middle of the runway where the barrier prevented further progress. When both animals had reached the center, the barrier was removed, permitting direct engagement. The contest ended when one $S$ was pushed back into his original starting area at which time he was promptly removed so that the winner could consume the pellet. Six daily trials were given. On the first two days, a social $S$ was tested against an isolated one. Order of pairings and the start box assignments were made at random. One pairing of each social with each isolate was given every day. On the last two days, isolates competed against isolates and socials against socials. Five trials per day were given and each $S$ within a given group was run once with every other $S$ in that group. Time taken to force the opponent out of the runway as well as which animal won the competition was recorded.

\section{RESULTS}

Mean start box and runway speeds during the eight days of runway training are shown in Table 1 for both isolated and socially reared Ss. Although the isolated Ss were slower in both measures, only runway speed reached statistical significance $(\mathrm{p}<.05$; Mann-Whitney $U)$. Two factors may have contributed to this finding. First, as indicated in Table 1 , isolated Ss were heavier than social and often had to squeeze through the narrow passageway. Secondly, they engaged in more competitive responses, including active exploration in the start box. While there was a decrease in starting and running times over trials for both groups, isolated Ss never attained speeds exhibited by the socials.

During the competition trials, which involved pairing twice every isolated $S$ with every social $S$, the isolates won 71 out of 72 bouts. Since there was a $75 \mathrm{~g}$ mean weight difference between the two groups, it might be assumed that weight rather than rearing condition would account for the isolates' greater number of wins. However, in 30 pairings within the social group, the heavier animals won 23 bouts while within

Table 1

Body Weight, Start Box and Runway Time of Socially and Socially Isolated Reared Male Rats

\begin{tabular}{|c|c|c|c|c|c|}
\hline \multirow{2}{*}{$\begin{array}{l}\text { Rearing } \\
\text { Condition }\end{array}$} & \multirow[b]{2}{*}{$\mathbf{N}$} & \multicolumn{2}{|c|}{ Body Weight (gm) } & \multicolumn{2}{|c|}{ Mean Time (sec) } \\
\hline & & Mean & Range & Start Box & Runway \\
\hline Social & 6 & 306 & $275-350$ & 18.5 & 3.1 \\
\hline Isolate & 6 & 387 & $353-414$ & 28.2 & 5.7 \\
\hline
\end{tabular}


the isolated group, the heavier animal won four out of 30 pairings. The mean time taken to win a bout when the isolates were paired against socials was $16 \mathrm{sec}$, when socials were paired against socials, $7 \mathrm{sec}$, and isolates against isolates, $25 \mathrm{sec}$.

\section{DISCUSSION}

The results of the present study indicate that socially isolated rats are more dominant than those reared in groups. Although the isolated group was heavier than the socially reared group, it appears that weight was not the major determining factor influencing winning in the competition test used in the present study. The one social S which was as heavy as the lightest isolated $\mathbf{S}$ lost all contests. Weight was actually a disadvantage to isolated animals competing against each other, since heavier animals lost $86 \%$ of their bouts. While it is true that heavier social animals tended to win when paired against lighter socials, it is suggested that this group's performance is not as good an index of dominance as the isolated animals'. The reason for this is provided by the order of running and the time taken to win in the competition situation. The social vs isolate pairings occurred first and the mean time to win was $16 \mathrm{sec}$. Since the isolated Ss almost always won, they formed strong habits or tendencies to proceed forward to the goal box. Only one isolated $S$ experienced back treading. Therefore, in the situation where two isolated Ss confronted each other, both had almost equal tendency to push forward and hence, a good contest developed. Indeed, this is reflected in the mean time taken to win for this group, which was $25 \mathrm{sec}$ : the longest required in any of the combinations of group pairings. On the other hand, social Ss in their initial experience typically lost. When paired against each other, retreating was likely to occur and apparently did so rapidly for one member of the pair. The mean time to resolve the contest and to enter the goal box was only $7 \mathrm{sec}$. Therefore. it is with the isolates that most competition existed and the heavier animals actually lost more of ten than the lighter ones.

In general the findings agree with those of Uyeno \& White (1967) in that socially isolated Ss dominate in a positive reward task as well as in a survival motivation paradigm. Both in the latter and the present study. the animals were not handicapped by being placed into a totally strange environment at the time of initial testing. In addition, the Ss in the present study had previous adult contact with members of the same species during the tests for sexual behavior. They were, therefore, not intimidated by sight of another rat, which otherwise would have constituted a completely novel stimulus, requiring extensive adaptation. It is more likely that under the present conditions, earlier developed behavior patterns predominated without the disruptive and confounding effects which novelty, surprise, and naivety might exert.
Two factors common between Uyeno \& White's (1967) and the present study, but different from most others. is the confining nature of the apparatus and the factors entering into establishing dominance. Competitive success in both situations depended more on the total body movement than fighting skill or oral aggression. The former factors favor isolated Ss, it could be argued. because they tend to be motorally hyperactive when in the presence of another rat (Gerall et al. 1967). In a confining condition this hyperactivity could lead to forceful forward motion. Further. as many other workers have suggested, social animals probably have larger response repertoires. These responses undoubtably include both retreating and fighting, neither of which the isolated Ss have ever experienced. In the latter group, the highest responses in the hierarchy would be exploration, movement. etc.. and in the case of fear, crouching. Each of these responses in a confined space is an effective antagonist to retreating. Further, isolated Ss with reduced response hierarchies would be expected to continue more rigidly the previously learned response of moving forward when confronted by the competing animal. It is necessary, therefore, to consider studies on dominance behavior from a procedural or situational point of view. It is possible that "dominance behavior" is not a single characteristic which remains stable from one type of test to the next. Rather, it is the structure of the particular environment interacting with organismic variables which determines whether an animal will win or lose, be submissive or aggressive.

\section{REFERENCES}

GERALL, H. D., WARD, I. L., \& GERALL, A. A. Disruption of the male rat's sexual behavior induced by social isolation. Animal Behaviour, $1967,15,54-58$.

GINSBURG, B., \& ALLEE, W. C. Some effects of conditioning on social dominance and subordination in inbred strains of mice. Physiological Zoology, 1942, 15, 485-506.

HUTCHINSON, R. R., ULRICH, R. E., \& AZRIN, N. H. Effects of age and related factors on the pain-aggression reaction. Journal of Comparative and Physiological Psychology, 1965, 59, 365-369.

KAHN, M. W. Infantile experience and mature aggressive behavior in mice: Some maternal influences. Journal of Genetic Psychology, 1954, 84, 65-75.

KING, J. A., \& GURNEY, N. L. Effect of early social experience on adult aggressive behavior in C57BL/10 mice. Journal of Comparative and Physiological Psychology, 1954, 47, 326-330.

ROSEN, J. Dominance behavior of the adult rat as a function of early social experience. Journal of Genetic Psychology, 1961, 99, 145-151.

UYENO, E. T., \& WHITE, M. Social isolation and dominance behavior. Journal of Comparative and Physiological Psychology, 1967, 63, 157-159.

\section{NOTE}

1. This research was supported by Research Grant HD 00867-05 from the National Institute of Child Health and Human Development, United States Public Health Service. 